\title{
Fuel Development for Gas-Cooled Fast Reactors
}

\author{
ANS Summer Meeting
}

\author{
M.K. Meyer \\ R. Fielding \\ J. Gan
}

June 2006

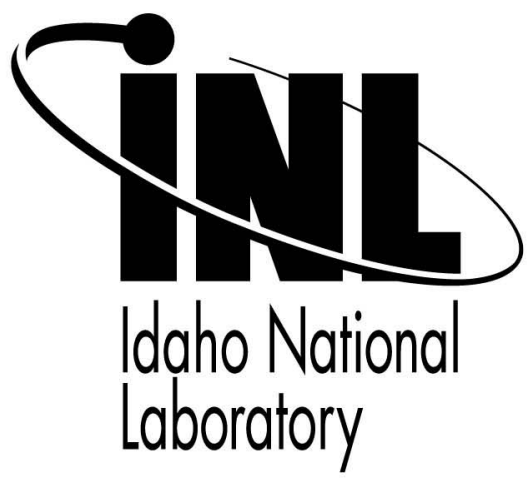

This is a preprint of a paper intended for publication in a journal or proceedings. Since changes may be made before publication, this preprint should not be cited or reproduced without permission of the author. This document was prepared as an account of work sponsored by an agency of the United States Government. Neither the United States Government nor any agency thereof, or any of their employees, makes any warranty, expressed or implied, or assumes any legal liability or responsibility for any third party's use, or the results of such use, of any information, apparatus, product or process disclosed in this report, or represents that its use by such third party would not infringe privately owned rights. The views expressed in this paper are not necessarily those of the United States Government or the sponsoring agency. 


\title{
Fuel Development for Gas-cooled Fast Reactors
}

\author{
M.K. Meyer, R. Fielding, J. Gan \\ Idaho National Laboratory, P.O. Box 1625, Idaho Falls, ID 83415
}

To be submitted to the Journal of Nuclear Materials as a contribution to a special issue documenting the Topical Meeting on Nuclear Fuels and Structural Materials for Next Generation Nuclear Reactors

June 6-8, 2006

Reno Nevada

INL/JOU-06-11592

Submitted for INL approval 26-Jul-06 


\title{
Fuel Development for Gas-cooled Fast Reactors
}

\author{
M.K. Meyer, R. Fielding, J. Gan \\ Idaho National Laboratory, P.O. Box 1625, Idaho Falls, ID 83415
}

\begin{abstract}
The Generation IV Gas-cooled Fast Reactor (GFR) concept is proposed to combine the advantages of high-temperature gas-cooled reactors (such as efficient direct conversion with a gas turbine and the potential for application of high-temperature process heat), with the sustainability advantages that are possible with a fast-spectrum reactor. The latter include the ability to fission all transuranics and the potential for breeding. The GFR is part of a consistent set of gas-cooled reactors that includes a medium-term Pebble Bed Modular Reactor (PBMR)-like concept, or concepts based on the Gas Turbine Modular Helium Reactor (GT-MHR), and specialized concepts such as the Very High Temperature Reactor (VHTR), as well as actinide burning concepts [1]. To achieve the necessary high power density and the ability to retain fission gas at high temperature, the primary fuel concept proposed for testing in the United States is a dispersion coated fuel particles in a ceramic matrix. Alternative fuel concepts considered in the U.S. and internationally include coated particle beds, ceramic clad fuel pins, and novel ceramic 'honeycomb' structures. Both mixed carbide and mixed nitride-based solid solutions are considered as fuel phases.
\end{abstract}

\subsection{Introduction}

The Gen IV GFR (Gas-cooled Fast Reactor) concept holds promise as an efficient and sustainable source of electricity and high-temperature process heat. Fast spectrum gascooled system concepts are designed to operate at much higher power density than thermal spectrum gas-cooled systems. Typical core power densities for thermal spectrum systems (High Temperature Gas Reactor, HTGR) are in the neighborhood of $6 \mathrm{MW} / \mathrm{m}^{3}$, while conceptual designs for GFR systems call for values in the range of $50-100 \mathrm{MW} / \mathrm{m}^{3}$. The higher power density requires a higher heavy metal density. The system of TRISO (tri-layer coated particle) fuel particles embedded in massive graphite blocks in thermal spectrum gas reactors is not adaptable to gas-cooled fast reactor concepts due to its low fissile loading, the high irradiation swelling behavior of graphite in a fast spectrum, and the excessive moderation due to the large graphite/fuel ratio.

The need for high fissile atom density, limitations on use of materials that are parasitic neutron absorbers in order to allow a conversion ratio of unity, and the requirement for fission product containment at high temperature during unprotected LOCA (loss of coolant accidents) events, limit the number of fuel types that can be realistically considered for GFR application. No fuels currently exist that meet GFR requirements, and little experimental data is available to support assessments of the feasibility of new fuels. 


\subsection{GFR fuel concepts}

\subsection{Screening criteria for GFR fuels}

Initial screening criteria for GFR fuel concepts were selected on the basis of satisfying GFR specific requirements developed on the basis of the Generation IV goals of sustainability, economics, proliferation resistance, and safety/reliability.

Based on Generation IV goals and the GFR fuel attributes derived from them, a simple set of screening criteria with a common basis among all fuels was selected for initial screening of fuel types; these criteria are listed in Table 1. More comprehensive requirements were developed for specific fuel types based on the results of core neutronic and thermohydraulic studies.

Table 1. GFR initial fuel screening criteria.

\begin{tabular}{|l|c|}
\hline \multicolumn{1}{|c|}{ Screening Criteria } & $\begin{array}{c}\text { Reference Value used for } \\
\text { Screening }\end{array}$ \\
\hline Melting temperature & $>2000^{\circ} \mathrm{C}$ \\
\hline Fuel heavy metal density & $>5 \mathrm{~g} / \mathrm{cm}^{3}$ \\
\hline Fuel burnup potential & $>5 \% \mathrm{HM}$ \\
\hline
\end{tabular}

The fuel temperature requirement, derived from the goal to exclude melting and vaporization under unprotected loss of flow conditions is the most limiting in terms of fuel selection, and when coupled with core neutronic requirements, severely limits the range of possible fuel materials. Obviously, current fuels such as zirconium-clad LWR fuel and stainless steel clad fast reactor fuels are excluded on the basis of cladding melting temperature. TRISO coated particle fuel is excluded on the basis of low heavy metal density. Burnup potential of fuels is somewhat more difficult to gauge, but does not appear to be overly restrictive. Based on these top level screening criteria, three categories of fuel have the highest potential for success; these are carbide and nitridebased composite-type (dispersion) fuels in the form of plates or blocks, pin-type refractory ceramic fuel, and novel plate type fuel structures. The latter fuels, under consideration primarily as part of the French GFR program, encapsulate single fuel pellets horizontally in individual honeycomb cells, the result being a higher heavy metal density than possible with dispersion fuel [2].

\subsection{Pin-type GFR fuel}

Many variants of pin-type fuels have been extensively developed for fast reactor service, and offer a large database on which to base estimates of fuel performance (although there are still sizable gaps). This fuel type currently has limitations in high temperature performance, however, due to the lack of a suitable refractory cladding material.

In the GFR, fuel response to the core conditions following a loss-of-coolant event is the overriding factor in the design of pin-type fuels. In typical pin-type fuels, a gas plenum is 
incorporated into the fuel pin to accommodate fission gas release. During GFR reactor operation at approximately $7 \mathrm{MPa}$ coolant pressure, fuel can be designed such that the net stress on the cladding is compressive throughout its service life; the coolant pressure is larger than the pin internal pressure. The plenum length is then a compromise between internal gas pressure that can be tolerated during core depressurization and shutdown and the coolant pressure drop through the core during operation. During an unprotected LOCA, however, core coolant pressure decreases coincident with both core and fuel temperature increases. This increase in fuel temperature causes increased fuel pin internal pressure due to both thermally driven pressurization and an increased fission gas release rate from the fuel. This increase in pin internal pressure, coupled with the lack of external pressure causes a large increase in cladding tensile hoop stress. This increase in stress occurs coincident with a decrease in cladding creep resistance and strength due to the cladding temperature increase. This combination of events during unprotected LOCA, coupled with core design constraints driven by plenum height restrictions make conventional sealed pin design for GFR fuel difficult. Alternatives to sealed fuel pin designs that alleviate the above problem include a common fission gas plenum in the low temperature region of the core, fuel pins containing rupture disks that allow pin depressurization to the coolant prior to ballooning, or vented fuel pins that allow the pin internal pressure to equalize with the core pressure via a filtered orifice.

Two primary factors are involved in the selection of the fissile phase for pin-type GFR fuel; these are core neutronic and fuel performance. Core neutronics calculations performed as a result of a U.S./French GFR INERI program [2] indicate that oxide fuel is a poor performer from the perspective of core neutronics relative to carbide and nitride fuels due to low heavy metal density and spectral softening due to the presences of oxygen. Excluding oxide fuel, the primary choices of fissile phase become mixed carbide and nitride fuels. Both fuels have been demonstrated to perform well to burnups on the order of $8-12 \%$ HM (Heavy Metal) in sodium cooled fast reactor systems [3]. These systems operate at lower cladding temperatures but higher power densities relative to current GFR requirements.

There are no outstanding considerations related to fuel behavior in the GFR environment that separate carbide and nitride fuels. At lower burnup, mixed nitride fuel swelling and gas release tends to be lower than that of carbide fuel. As burnup increases, however, these differences in gas release and swelling behavior decrease. A potential issue is the need for ${ }^{15} \mathrm{~N}$ enrichment (and $\mathrm{N}$ recycle) of nitride fuel for reasons of neutron economy in the GFR system. The presence of ${ }^{14} \mathrm{~N}$ strongly affects core breeding performance [2]. The order of magnitude to which this additional expense effects fuel cycle cost are a source of significant uncertainty which favor the use of carbide fuel. It is likely, however, that the overriding factor in fissile phase (pellet) selection for a pin-type concept will be driven by cladding compatibility, a fuel performance consideration.

The goal to prevent core restructuring coupled with core neutronic requirements limits the potential choice of cladding materials. Alloy base-metals and other materials that meet the $2000^{\circ} \mathrm{C}$ melting temperature requirement are $\mathrm{B}, \mathrm{C}, \mathrm{Nb}, \mathrm{Mo}, \mathrm{Ru}, \mathrm{Hf}, \mathrm{Ta}, \mathrm{W}, \mathrm{Re}$, Os, and Ir. Boron and hafnium are not practical materials for this application due to their 
effect on core neutron economy and that $\mathrm{Ru}, \mathrm{Os}$, and Ir are not practical due to cost and availability. Scoping core neutronics studies have also shown that cores clad with Ta, W, and Mo require very large heavy metal inventories to allow self breeding. Carbon and carbon/carbon composites have a service life of less than 15 dpa [4], compared to the 80 dpa required to achieve target fuel burnup (5\% HM), and are also excluded.

The remaining allowable alloy base metal, $\mathrm{Nb}$, was developed in alloy form as $\mathrm{Nb}-1 \mathrm{Zr}$ and PWC-11 (Nb-1Zr-0.06C) during the SP-100 space reactor program. Many fuel irradiation experiments have been conducted using variants of $\mathrm{Nb}-\mathrm{Zr}$ cladding and $\mathrm{UN}$ fuel to burnups of approximately $6 \%$ in fast spectrum environments [5]. Neutronic performance of $\mathrm{Nb}-1 \mathrm{Zr}$ clad fuel encased in $\mathrm{Nb}-1 \mathrm{Zr}$ ducts is marginal, but improves when $\mathrm{Nb}$ is not used as the duct material [6]. Concerns related to the use of Nb-based alloys are catastrophic oxidation in case of air ingress and alloy sensitivity to coolant impurities.

$\mathrm{SiC}$ is another potential cladding choice for GFR, although at a much earlier stage of development. Joining of $\mathrm{SiC}$ to $\mathrm{SiC}$ or other materials is a major issue confronting development of SiC cladding. The NITE (Nano Infiltration Transient Eutectic) process [7] and CVI (Chemical Vapor Infiltration) of a fiber preform woven over a monolithic $\mathrm{SiC}$ tube [8] are two methods for cladding fabrication currently under development. SiC cladding is most compatible with mixed carbide fuel. Reaction of $\mathrm{SiC}$ with UN is thermodynamically favorable above $550^{\circ} \mathrm{C}$, although reaction could presumably be prevented through the use of a cladding liner. SiC composites have demonstrated good irradiation behavior [9] and should be capable of maintaining mechanical properties at radiation damage levels beyond $50 \mathrm{dpa}$ at temperatures of less than $1000^{\circ} \mathrm{C}$.

\subsection{Dispersion fuel}

Dispersion fuels (also referred to as composite fuels) offer the potential to reach goal burnup and offer more flexibility in choice of materials than pin-type fuel concepts. These fuels consist of a distribution of discrete fuel particles embedded in a non-fuel matrix. Macrodispersions are thus preferred for the dispersion fuel concept currently envisioned for the GFR. In the ideal case, the matrix remains largely unaffected by neutron, fission fragment, and $\alpha$-particle damage from the fission events that take place in the fuel particles. The concept most likely to be successful for composite fuel will use coated particles (or elongated elliptical 'rods') embedded in an inert matrix.

The simplest dispersion fuel concept, and the one with the highest potential fuel loading, consists simply of a (non-buffered) fuel particle embedded in an inert matrix. Such particles typically include a distribution of approximately $15 \%$ open porosity to act as a fission gas 'plenum' reducing the gas-driven pressure on the matrix. Dispersions using this concept have been proven to work well in combination with ductile matrices such as steel [10] and niobium [11]; performance has been postulated to be limited by a combination of fission density and temperature [12]. Analysis of GFR fuel requirements, however, eliminates metal alloys from consideration (see below). Several irradiation tests have been conducted using oxide matrix fuel test specimens in France $[13,14]$ and 
Japan [15]. Matrix cracking has been observed in all of these cases, leading to higher than expected fission gas release. This behavior has been attributed to stresses imposed on the matrix both from fuel particle swelling and the differences in thermal expansion coefficient between the fuel particles and the matrix. The so-called 'jingle' variant of the macrodispersed concept, which incorporates free space between the fuel particle and matrix reduced matrix fracture due to fuel/matrix mechanical interaction, although some matrix cracking was still observed [16].

Given the available cermet irradiation behavior database, the concept most likely to minimize fission gas release to the coolant will incorporate 'buffered' particles in a dense matrix. Here each particle is surrounded by a low density layer of material with low crush strength. This 'buffer' material serves the dual role of providing volume for fission gas and providing volume for fuel particle swelling. The buffer layer is protected by a dense coating layer, also designed to provide for fission product retention. In this way, there are three barriers to fission product release to the coolant. These are the coating around the particle, the dense matrix, and the cladding around the dispersion fuel block. The use of coated particles makes it more difficult to achieve high heavy metal density in the fuel. Since fuel particle volume increases in proportion to the cube of the particle radius, the net heavy metal density within a fuel particle falls rapidly with increasing coating thickness. This fact requires that the coating thickness to kernel diameter ratio be kept as small as possible while maintaining utility as a fission product barrier.

The most likely fissile particle types for composite fuels are (U,Pu)C and (U,Pu)N due to the combination of high melting temperature and high actinide density. Although a dispersion of nitride fuel particles may initially exhibit lower fission gas release than the carbides, the same questions remain related to the use of nitrogen enriched in ${ }^{15} \mathrm{~N}$ in the fuel matrix as in pin-type fuels. Because of the poor irradiation performance of pyrocarbon at high fast fluence, the use of a low density pyrocarbon buffer layer is questionable. Low density carbide and nitride coatings with low crush strength deposited from non-halide precursors may be more suitable. Chemical compatibility issues favor the use of a nitride coating system ( $\mathrm{TiN}$ or $\mathrm{ZrN}$ ) for mixed nitride kernels and a carbide coating system ( $\mathrm{SiC}$ or $\mathrm{ZrC}$ ) for mixed carbide kernels. There has been some recent development of TiN-based coatings [17]. $\mathrm{ZrC}$ has undergone irradiation testing as a coating on TRISO fuel, and may have superior retention of some fission products, especially at high-temperature [18], however, there is a much larger database available for fabrication, properties, and irradiation behavior of SiC coatings [19].

Considering elemental matrix materials, few meet the melting temperature criterion of $2000^{\circ} \mathrm{C}$, and those that do are neutronically unacceptable due the negative impact that these materials have on core heavy metal inventory and safety parameters. Scoping core neutronics studies [2] have shown that the use of the refractory metals Mo, Ta, W, and Re is not practical due to neutronic penalties associated with the high absorption cross sections of these materials that make it difficult or impossible to meet GFR design goals in terms of core heavy metal inventory, core safety parameters, or known irradiation performance limitations. These considerations drive the choice of matrix materials into the realm of ceramics or intermetallic compounds. 
There are thousands of possible binary, ternary, and higher ceramics and intermetallic materials. Well characterized material property and irradiation behavior data is not available for the majority of these, and little can be said about the suitability for use in the GFR fuel environment. Many of the refractory carbides and nitrides are disqualified due to unsuitable neutronic properties. After consideration of initial screening criteria, a few materials emerge that have the potential to meet GFR fuel matrix material requirements. These are zirconium carbide $(\mathrm{ZrC})$, titanium carbide $(\mathrm{TiC})$, silicon carbide $(\mathrm{SiC})$, zirconium nitride $(\mathrm{ZrN})$, titanium nitride (TiN), and possibly aluminum nitride (AIN).

Of these materials, $\mathrm{SiC}$, specifically the cubic $\beta$-SiC phase, offers the largest existing database in terms of material properties, irradiation behavior, and fabrication. $\mathrm{SiC}$ has excellent oxidation resistance due to rapid formation of a dense, adherent $\mathrm{SiO}_{2}$ surface scale on exposure to air at elevated temperature, which offers protection from further oxidation. The irradiation swelling behavior of $\mathrm{SiC}$ is well documented. The understanding of the irradiation behavior of SiC-based composite materials is also maturing [20]. Processing of $\mathrm{SiC}$ into dense shapes is currently done on an industrial scale at a reasonable cost, although major modifications will be required for processing of particle fueled composites. Other properties of $\mathrm{SiC}$ appear to be adequate for GFR service, with the possible exception of fracture toughness. Fracture toughness and thermal shock resistance are issues that must be addressed for all ceramic materials through the use of microstructural designs that incorporate stable barriers to crack growth into the matrix.

Because of the acceptable properties of $\mathrm{SiC}$, the large irradiation behavior database, the preference of core designers for $\mathrm{SiC}$ over refractory metals, and the experience in use of $\mathrm{SiC}$ as a component in TRISO fuel, a dispersion of $(\mathrm{U}, \mathrm{PuC})$ particles coated with a bilayer $\mathrm{SiC}$ coating in a $\mathrm{SiC}$ matrix was selected as the reference GFR fuel concept for testing in the United States. This selection is made with the realization that fuel density is marginal and that improvements in fracture toughness are required. Fuel parameters initially selected for GFR fuel testing are listed in Table 2. Outer coating thicknesses have been specified to protect the buffer layer during handling of the coated particles. In order to increase particle packing density, a dual sized distribution of particles is specified. 
Table 2. Reference GFR dispersion fuel parameters

\begin{tabular}{l|l}
\hline \multicolumn{1}{c|}{ Parameter } & \multicolumn{1}{c}{ Reference Value } \\
\hline \hline Fuel particle type & Bi-layer SiC coated $(\mathrm{U}, \mathrm{Pu}) \mathrm{C}$, Two size distribution \\
& (1) $1.64 \mathrm{~mm}$ diameter \\
Inner coating & (2) $480 \mu \mathrm{m}$ diameter \\
& Buffer layer of $\mathrm{SiC}$ with $\mathrm{TD}<30 \%$ and low crush strength \\
& (1) buffer thickness $\sim 58 \mu \mathrm{m}$ \\
Outer coating & (2) buffer thickness $\sim 17 \mu \mathrm{m}$ \\
& Dense CVD $\mathrm{SiC}$, \\
& (1) thickness $\sim 61 \mu \mathrm{m}$ \\
Fuel kernel & $(2)$ thickness $\sim 18 \mu \mathrm{m}$ \\
& $(\mathrm{U}, \mathrm{Pu}) \mathrm{C}$ \\
Heavy metal density & $(1) 1.4 \mathrm{~mm}$ diameter \\
& $(2) 410 \mu \mathrm{m}$ diameter \\
Matrix & $6 \mathrm{~g} \mathrm{HM} \cdot \mathrm{cm}^{-3}, 75 \%$ particle loading \\
\hline
\end{tabular}

\subsection{GFR fuel fabrication}

Since the GFR is being considered as the reactor component of a closed fuel cycle system, burning minor actinides from self recycled fuel or from thermal spectrum reactors, GFR fuel must be amenable to remote (or semi-remote) processing. In the case of full actinide recycle or burning of actinides from outside sources, fully remote and shielded fabrication processes inside of a hot cell are likely to be required. The entire fuel fabrication process must be compact, simple, and efficient in order to allow economical remotization. Generation of TRU waste must be minimized or schemes implemented that allow efficient recycle of TRU-bearing waste streams. These issues must be considered in design of the fuel and the fuel fabrication process. Recent work on GFR fuel fabrication has been reported in more detail by Fielding [21].

Uranium carbide fuel microspheres have been fabricated by the rotating electrode atomization process. Use of these particles requires coating through a process somewhat analogous to TRISO fuel. In the case of the GFR, however, the coating must be thin to maximize fuel loading. It is also postulated that a pyrocarbon coatings should be eliminated in favor of a low-density $\mathrm{SiC}$ buffer coating. In the TRISO fuel system, $\mathrm{SiC}$ is applied using a methyltrichlorosilane precursor to $\mathrm{SiC}$. The use of halide precursors to deposit coatings over uranium kernels however, is known to facilitate transport of uranium from the kernel into the coating layers, resulting in decreased coating performance and fission product release into the coolant. A non-halide precursor is thus likely to be required for deposition of the buffer layer. Investigations into the deposition of low density buffer layers and seal coatings using methylsilane [22, 23] (a non-halide precursor to $\mathrm{SiC}$ ) onto surrogate fuel particles have shown the feasibility of this approach. 
In order to fabricate the dispersion fuel, coated particles must be assembled into a reasonably uniform distribution in the selected matrix material. For $\mathrm{SiC}$ matrix fuel, this may be accomplished by assembling coated particles into a packed bed and then infiltrating the bed with a carbonaceous precursor [24]. The precursor is then converted by pyrolysis to carbon. The converted matrix is infiltrated with molten silicon, and thermally treated to allow reaction of the silicon with carbon to form SiC. Many variations on this method are possible, including substitution of a portion of the $\mathrm{SiC}$ outer shell with pyrocarbon in order to encourage bonding of the matrix to the fuel particles, or treating the particles to discourage bonding to the matrix. This infiltration technique has been used to fabricate fuel specimens during the high temperature AGR (Advanced Gas Reactor) fuel development program in Great Britain. Dispersions of pyrocarbon coated particles in a $\mathrm{SiC}$ matrix were formed by reaction bonding and successfully irradiated at temperatures of $750-1200^{\circ} \mathrm{C}$ and rod powers to $39 \mathrm{~kW} / \mathrm{m}$ in two experiments [25]. Burnup values ranged from 1.6 to 5\% FIMA. Fractional fission gas release was measured during low burnup tests, and was on the order of $10^{-6}$.

\subsection{Irradiation testing}

Due to the extremely complex nature of fuel behavior under irradiation, fuel irradiation testing is necessary for determination of the viability of new fuel concepts; without irradiation test data, no definitive statement about viability can be made. This is especially true for the GFR, where operating parameters and fuel physical requirements are outside of the envelope of the current experimental fuel database.

Irradiation testing for GFR fuel consists of separate effects testing of matrix material and fuel specimens. The GFR-F1 irradiation test contains the candidate GFR matrix materials listed in Table 2, and was inserted into the Advanced Test Reactor in February 2004. Irradiation of this test will continue into 2007, and will provide information about matrix material behavior at relatively low damage rates at $800^{\circ} \mathrm{C}$.

The FUTURIX-MI irradiation test is an irradiation test in the Phénix fast reactor conducted jointly with the French CEA. This experiment also contains the candidate matrix materials listed in Table 2 (as well as other materials of interest to GFR) in several geometries to allow for postirradiation measurement of mechanical properties, density, microstructure, thermal diffusivity, and thermal expansion. Insertion of this experiment is scheduled for mid 2007. Experimental specimens will be irradiated at $900-1000^{\circ} \mathrm{C}$ and withdrawn from the reactor in early 2009 after 240 EFPDs (Effective Full Power Days) at a dose of approximately $42 \mathrm{dpa}$ in $\mathrm{SiC}$.

Ion irradiation tests of matrix materials has been conducted with $1 \mathrm{MeV}$ krypton ions at $800^{\circ} \mathrm{C}$ to $70 \mathrm{dpa}$. It was found that the microstructural stability of $\mathrm{TiC}$, TiN, and $6 \mathrm{H} \mathrm{SiC}$ was better than that of $\mathrm{ZrC}$ and $\mathrm{ZrN}$. $\mathrm{ZrC}$ and $\mathrm{ZrN}$ exhibit increases in lattice parameter on the order of $7-9 \%$, while $\mathrm{TiC}$, and $\mathrm{TiN}$ exhibit increases of about $2 \%$ [26].

Originally a part of the GFR fuel development program, irradiation testing of fueled SiC matrix GFR dispersion fueled specimens are no longer planned in the United States as a 
result of the recent shift in emphasis to development of sodium-cooled reactors for actinide burning.

\subsection{Conclusions}

No fuels currently exist that meet Generation IV GFR requirements, and little experimental data is available to support assessments of the feasibility of new fuels. GFR fuel concepts and materials that meet GFR requirements have been proposed. All of the processes necessary for fabrication of fuel specimens for irradiation testing have been demonstrated using either uranium or non-radioactive surrogate materials. Due to the complex nature of fuel behavior under irradiation, fuel irradiation testing is necessary to determine viability of fuel concepts. A program of irradiation testing of candidate fuel matrix materials is underway in the Advanced Test Reactor and the Phénix reactor. This testing is supplemented out-of-pile by ion irradiation damage studies.

\section{References}

[1] A Technology Roadmap for Generation IV Nuclear Energy Systems, U.S. DOE Nuclear Energy Research Advisory Committtee and the Generation IV International Forum, December (2002).

[2] System Design Report, Development of Generation IV Advanced Gas-Cooled Reactors with Hardened/Fast Neutron Sectrum, INERI Report GFR023, February (2005). [3] see for example, J. Nucl. Mater. 204 (1993).

[4] L.L. Snead, J.W. Klett, "Ceramic Composites for Structural Applications," Proc. GLOBAL 2003, American Nuclear Society (2003) 1077-1078.

[5] see for example B.J. Makenas, J. W. Hales, A.L. Ward, "Fuels Irradiation Testing for the SP-100 Program," Proc. $8^{\text {th }}$ Symposium on Space Nuclear Power Systems, AIP (1991) 886-891.

[6] E.A. Hofman, T.A. Taiwo, "Physics Studies of Preliminary Gas-Cooled Fast Reactor Designs," Proc. GLOBAL 2003, American Nuclear Society (2003) 82-91.

[7] H. Kishimoto, T. Hinoki, K. Ozawa, K.-H. Park, S. Kondo, A. Kohyama, "Dimension Stability Analysis of NITE SiC/SiC Composite Using Ion Bombardments for the Investigation of Reliability as Fusion Materials," Ceramic Engineering and Science Proceedings, eds. M. Brito, P. Filip, C. Lewisohn, A. Sayir, M. Opeka, W. Mullins, vol. 26, issue 8 (2005) p. 215-222.

[8] Gamma Engineering Proposal to DOE for FY-2003 SBIR Phase 1 Solicitation, "Development of a Hybrid SiC/SiC Ceramic Composite for Gas Cooled Fast Reactor Fuel Cladding and Core Structurals," January, 2003.

[9] S.J. Zinkle, "Nonfissile Ceramics for Future Nuclear Systems," Proc. GLOBAL 2003, American Nuclear Society (2003) 1066-1067.

[10] see for example, J.D.B. Lambert, "Irradiation Study of $\mathrm{UO}_{2}-$ Stainless Steel and $(\mathrm{Pu}, \mathrm{U}) \mathrm{O}_{2}$-Stainless Steel Cermet Fuels in Rod and Plate Geometry," p. 237-254 in High Temperature Nuclear Fuels, Metallurgical Society Conference Vol. 42, ed. A.N. Holden, Gordon and Breach (1966).

[11] D.L. Keller, G.W. Cunningham, W.E. Murr, E.O. Fromm, D.E. Lozier, "HighTemperature Irradiation Test of $\mathrm{UO}_{2}$ Cermet Fuels,” report BMI-1608 (1963). 
[12] W.C. Thurber, F.R. McQuilkin, E.L. Long, M.F. Osborne, "Irradiation Testing of Fuel for Core B of the Enrico Fermi Fast Breeder Reactor," report ORNL-3709 (1964). [13] Neeft, E.A.C., Bakker, K., Schram, R.P.C., Conrad, R., Konings, R.J.M., "The EFTTRA-T3 Irradiation Experiment on Inert Matrix Fuels," J. Nucl. Mater. 320 (2003) 106-116.

[14] Georgenthum, V., Chauvin, N., Pelletier, M., Noitor, J., Berlanga, C., Brenet, D., "Influence of the Microstructure for Inert Matrix Fuel Behaviou: Experimental Results and Calculations," Proceedings of the GLOBAL 99 International Conference on Future Nuclear Systems, Jackson Hole, WY USA August 29-September 3, (1999).

[15] Nitani, N., et al., "In-pile irradiation of rock-like oxide fuels", J. Nucl. Mater. 319 (2003) 102.

[16] Noirot, J., Desgranges, L., Chauvin, N., Georgenthum, V., "Postirradiation Examinations of THERMHET Conmposite Fuels for Transmutation," J. Nucl. Mater. 320 (2003) 117-125.

[17] R.A. Lowden, J.C. McLaughlin, J.R. Kelley, "Nitride Ceramic Coatings for GasCooled Fast Reactor Particle Fuel," Proc. GLOBAL 2003, American Nuclear Society (2003) 523-524.

[18] Minato, K., Ogawa, T., Fukuda, K., Sekino, H., Kitagawa, I., Mita, Naoaki, "Fission Product Release from ZrC-coated Fuel Particles During Postirradiation Heating at 1800 and $2000^{\circ}$ C," J. Nucl. Mater. 249 (1997) 142-149.

[19] For a comprehensive review of the state of the art with respect to coated particle fuels circa. 1977 see, Nucl. Tech. 35, No. 2 (1977).

[20] S.J. Zinkle, "Nonfissile Ceramics for Future Nuclear Systems," Proc. GLOBAL 2003, American Nuclear Society (2003) 1066-1067.

[21] Fielding, R., "Gas Fast Reactor Fuel Fabrication," this proceedings.

[22] Miller, J., Oak Ridge national Laboratory, personal communication.

[23] Slaga, A., "Chemical Vapor Deposition of Porous Silicon Carbide onto Ceramic Microspheres Using a Fluidized Bed Reactor," Master's Degree Thesis, Purdue University (2006).

[24] see for example E.E. Hucke, U.S. Patent 3,859,421, "Methods of Producing Carbonaceous Bodies and the Products Thereof," Jan. 7, 1975.

[25] J.V. Shennan, "Dispersed Ceramic Fuels for the Advanced Gas-Cooled Reactor," p. 96-110 in Preparation of Nuclear Fuels, Nuclear Engineering Part XVIII, eds. A.D.

Tevebaugh and D.L. Keller, Chemical Engineering Progress Symposium Series No. 80, Vol. 63 (1967).

[26] J. Gan, M.K. Meyer, R.C. Birtcher, T.R. Allen, "Microstructure Evolution in ZrC Irradiated with Kr Ions," J. ASTM Int. [3] 4 (2005). 